\title{
El tema de género en las convenciones colectivas en Venezuela
}

\author{
Iranzo, Consuelo* \\ Richter, Jacqueline**
}

\section{Resumen}

El objetivo de este artículo es evaluar la atención que le ha prestado la convención colectiva en Venezuela a la regulación de los problemas que derivan de la condición de género y, en particular los relativos al trabajo femenino, partiendo de considerar que dicho instrumento es el más idóneo para confrontar la desigualdad de oportunidades presentes en el mercado de trabajo. Se presenta un breve diagnóstico del contexto actual de la negociación colectiva en nuestro país y los avances de la legislación en materia de la mujer en el trabajo, posteriormente se analizan las cláusulas de las convenciones colectivas de sectores claves en tres ámbitos: a) maternidad/ paternidad y cuidado infantil; b) condiciones de trabajo de la mujer y relaciones de género; c) equidad de género y no discriminación. Dicha investigación permitió detectar los temas sobre los cuales se ha focalizado la atención, como es el de la licencia de maternidad y aquellos donde se observan los mayores vacíos, como es el de las condiciones de trabajo. La cultura del incumplimiento, la escasa participación sindical femenina y la poca conciencia de género, son parte de los problemas que conspiran contra una mayor intervención de la convención colectiva en estos asuntos.

Palabras clave: Convención colectiva, género, mujer trabajadora, acción sindical, OIT.

\section{The Gender Theme in Collective Conventions in Venezuela}

\section{Abstract}

The objective of this article is to evaluate the attention given to the regulation of problems arising from the gender condition in collective labor conventions in Venezuela, and in particular those relative to female labor, beginning with the consideration of the most ideal instrument to confront the

\section{Recibido: 02-10-21 . Aceptado: 03-05-07}

Socióloga del Trabajo, profesora-investigadora del Centro de Estudios del Desarrollo (CENDES) de la Universidad Central de Venezuela (UCV). Miembro del PPI.

E-mail: ciranzo@reacciun.ve

** Abogada, profesora de Sociología Jurídica de la Facultad de Ciencias Jurídicas y Políticas de la UCV e investigadora del Instituto de Derecho Privado de la misma facultad. Miembro del PPI. 
inequality of opportunity that presently exists in the labor market. A brief diagnosis of the present work context in Venezuela is presented as well as advances in legislation in relation to female labor, and then the clauses found in collective bargaining efforts of key sectors are presented in relation to: a) maternity, paternity and child care; b) work condition for women in relation to gender; and c) sex equality and non-discrimination. This paper permits the detection of themes on which attention has been focused, such as maternity licensing and others that present attention, such as work conditions. The culture of non-fulfillment of agreements, the lack of female participation in labor unions, and the low consciousness in relation to gender are all part of the problem that conspires against a greater intervention in collective agreements in relation to these elements.

Key words: Collective conventions, gender, women laborer, union action, OIT.

\section{Introducción}

En nuestro país, la situación de la mujer ha sido abordada con políticas públicas fundamentalmente vinculadas con lo que han sido los principales temas de la agenda de los grupos feministas, como son los de la esfera doméstica y la participación política; es decir, la acción del Estado y de las organizaciones de mujeres ha estado centrada en los problemas de protección infantil, maltrato, violencia, embarazo precoz y en los últimos tiempos salud reproductiva y SIDA, y en promover la participación política de la mujer. Un ámbito distinto, como es el de la participación femenina en el mercado de trabajo ha recibido menor atención y sin embargo no es un asunto menos importante, pues la mujer sigue sufriendo situaciones que la colocan en condiciones desfavorables frente al hombre. Pero tal circunstancia no será posible de ser superada mientras los asuntos relativos a la reproducción de la especie y al cuidado de la familia sigan siendo entendidos como problemas exclusivos de la responsabilidad femenina y no como asuntos que conciernen tanto al hombre como a la mujer y, por ende, a la sociedad en su conjunto, tal como se han preocupado por remarcar los estudios de género.

Así como se requiere del establecimiento de principios jurídicos equitativos para el tratamiento de los asuntos relativos a ambos sexos, como paso indispensable para atacar las iniquidades existentes en el mercado de trabajo, se necesitan, en el campo de la acción cotidiana, también de otros medios que puedan profundizar las conquistas legales obtenidas y regularlas más directamente en la práctica laboral. Y el instrumento privilegiado para ello es la negociación colectiva. La convención colectiva, como fruto de esa negociación, está llamada a ejercer un papel crucial en el establecimiento de la igualdad de oportunidades para el conjunto de la fuerza de trabajo, de la misma manera que lo ha hecho para mejorar la distribución del ingreso, cuya importancia se evidencia al observar como su debilitamiento ha venido aparejado del aumento de las iniquidades sociales.

El objetivo de este artículo es evaluar la atención que le ha prestado la convención colectiva en Venezuela a tales asuntos. En un artículo anterior, publicado en esta misma revista (Iranzo y Richter, 2002a) sintetizamos, a partir de 
la bibliografía existente en la materia y de nuestras investigaciones al respecto, los principales problemas que afectan a la mujer trabajadora y que deberían ser abordados por la negociación colectiva. La intención de dicho artículo fue el de servir de marco teórico al trabajo que presentamos a continuación, que es básicamente de carácter empírico ${ }^{1}$. Por tal razón, a lo largo de nuestra exposición iremos retomando los aspectos que desarrollamos en el artículo anterior, de manera de evaluar en qué medida los asuntos relativos al género tienen cabida dentro de nuestra negociación colectiva.

Tanto este artículo como el que le precede tienen su origen en una investigación que realizáramos para la Organización Internacional del Trabajo (Iranzo y Richter, 2002b), como parte de un estudio comparativo de la negociación colectiva en América Latina desde una perspectiva de género. El objetivo de dicho estudio, coordinado por Lais Abramo, ha sido el de analizar la incorporación de los temas relativos a la mujer trabajadora y a las relaciones de género en el trabajo en los procesos de negociación colectiva².

La importancia que le adjudicamos a un estudio de esta naturaleza es tanto de carácter teórico como de carácter práctico. De carácter teórico, porque dar- le visibilidad a los problemas derivados de las diferencias de género tiene consecuencias en el campo de la teoría de la sociología del trabajo, en tanto contribuye a "repensar el propio concepto de trabajo y las múltiples realidades que están relacionadas con éste" (Abramo, 1998:41). De carácter práctico, porque, al poner en evidencia los vacíos que persisten en la esfera de la regulación del trabajo femenino, se contribuye a perfilar líneas estratégicas de acción futura a seguir por parte del movimiento sindical y de los interesados en las causas de los trabajadores para favorecer una mayor equidad dentro del sistema de relaciones laborales.

\section{El contexto de la negociación colectiva en la actualidad}

La negociación colectiva en Venezuela enfrenta retos similares a los que se presentan en otros países de la región, como es su inserción y desarrollo en un contexto desfavorable a su promoción y extensión, básicamente como consecuencia de las profundas y radicales transformaciones que han sufrido los mercados de trabajo en los últimos decenios del siglo XX (De la Garza, 2000). La recesión económica, la reestructuración productiva y la necesidad de bajar los costos laborales para enfrentar la apertu-

1 Por razones de espacio, no era posible publicar ambos trabajos conjuntamente Por tal razón, sugerimos a los interesados en conocer los planteamientos de carácter más teórico que están detrás de esta temática, revisar el artículo previo mencionado.

2 Proyecto regional denominado: "Negociación colectiva y equidad de género en América Latina", promovido por la Oficina Regional de la OIT para las Américas y la Oficina de Actividades para los trabajadores (ACTRAV) de la OIT (2001-2002). 
ra económica han tenido consecuencias determinantes sobre los procesos de negociación colectiva. La disminución del peso de los asalariados dentro de la fuerza de trabajo, la informalización, la externalización de los costos laborales, la individualización de las relaciones de trabajo y la precarización resultante, son fenómenos que están incrementando progresivamente el número de trabajadores fuera del alcance de la negociación colectiva. Para el año 1998, la negociación colectiva en nuestro país cubría nada más al $27 \%$ de los asalariados, los cuales a su vez representaban el $59 \%$ del total de los ocupados $^{3}$.

A la disminución de los trabajadores amparados por la negociación colectiva por efecto de la perdida de centralidad del trabajo asalariado y del crecimiento constante de la informalización del mercado de trabajo, se le suma la disminución provocada por los procesos de externalización de los costos laborales: por una parte, la figura de trabajo independiente y la simulación del trabajo subordinado, mediante la celebración de contratos civiles o mercantiles, están reduciendo drásticamente el número de trabajadores con condición de asalariados; por la otra, la subcontratación, a través de agencias de empleo, cooperativas o pequeñas empresas, va ampliando el segmento de trabajadores que no tienen acceso a la sindicalización y por ende a la negociación colectiva (Dombois, 1999). Todo ello ha ido afectando profundamente a ésta última, pues ha pasado a ser la expresión social de los intereses de un sector privilegiado, al mismo tiempo que la ha debilitado en su interior. La precariedad que rodea a los trabajadores fijos los conduce a moderar sus reivindicaciones, obligándolos a valorar muy fuertemente el puesto de trabajo con protección social del cual gozan e introduce, por tanto, un elemento distorsionador hacia la baja en los montos salariales. La informalización y la individualización de la relación de trabajo al tiempo que han reducido la base de afiliación tradicional del movimiento sindical, restándole fuerza para negociar, han restringido el alcance y el ámbito de aplicación del convenio colectivo.

La negociación colectiva enfrenta, también, la disminución del peso del sector público dentro de la fuerza de trabajo, bastión tradicional del movimiento sindical venezolano. Muchos de los avances en la protección se iniciaron en este sector, siendo tradicional que cuando una institución se arraigaba en su interior, pudiese ser extendida al sector privado con mayor facilidad. Fue el caso de la regulación convencional de la estabilidad laboral, los permisos sindicales, las becas por hijos, por citar los beneficios más conocidos y recurrentes. De tal manera que su reducción termina lesionando el efecto de irradiación de su negociación colectiva hacia el sector privado.

El contrato colectivo es visualizado por las empresas como una camisa de fuerza que les impide competir con base en mano de obra barata, por lo que tienden a evadirla en la medida de los posi- 
ble. La década de los noventa presenta un cuadro desolador en cuanto a convenios colectivos celebrados, habiéndose producido una reducción tan drástica que de 1461 convenios colectivos celebrados en 1990 se pasó a menos de cien en el año 2000 , lo que representa el $15 \%$ de los celebrados a los inicios de la década, lo que puede observarse en la Tabla 1.

Cuando la negociación colectiva tiene lugar, el esfuerzo empresarial ha estado dirigido a reducir los temas de la negociación. Los argumentos relativos a los costos, la recesión y la crisis de la empresas, así como a la situación de privilegio en que se encuentran los asalariados con negociación colectiva, aparecen con frecuencia en la mesa de negociaciones para frenar la mejora en las condiciones laborales. Frente a esto, el sindicalismo se encuentra con una deteriorada capacidad de negociación. A los factores mencionados anteriormente que han debilitado al movimiento sindical se le suman sus propias deficiencias, de manera que desde comienzos de la década de los noventa se viene observando en nuestro país un proceso de crisis de las organizaciones sindicales (Iranzo y Patruyo, 2001). La estrategia sindical, en este contexto, ha sido en muchas ocasiones tratar de salvaguardar el empleo y el convenio colectivo a cualquier costo. Ante la posibilidad de perder el instrumento de protec- ción que representa éste, a menudo se ha aceptado restringir los temas de negociación, incluso eliminar las conquistas obtenidas para conformarse con los mínimos estipulados por la ley, negociar mínimas modificaciones o dar ultra actividad (prorrogar) a un convenio ya vencido, pues la fuerza con la que cuentan no les permite mayores aspiraciones.

En este contexto de pérdida de espacios de la negociación colectiva, de precarización de las condiciones de trabajo de amplias capas de trabajadores, de defensa de lo obtenido más que de búsqueda de nuevas conquistas, el ingreso de nuevos temas en la agenda de negociaciones es muy difícil; no es un momento de apertura y avances, sino de retrocesos (Abramo, 2001). Todos estos elementos, de enorme importancia, hay que tenerlos presentes en el momento de evaluar la incorporación de asuntos tales como el de género en nuestras convenciones colectivas.

\section{El tema de la mujer en la agenda pública}

La regulación del tema de la mujer tuvo en nuestro país un impulso especial en la década de los noventa en el campo de la legislación. La Ley del Trabajo promulgada en 1990 aumentó los lapsos de licencias de maternidad de 12 a 18 semanas, pero además, avanzó considerable-

\section{Tabla 1}

\section{Convenciones colectivas de trabajo celebradas entre 1990 y el 2000}

\begin{tabular}{ccccccccccc}
\hline 1990 & 1991 & 1992 & 1993 & 1994 & 1995 & 1996 & 1997 & 1998 & 1999 & $2000 p-/$ \\
\hline 1.461 & 1.210 & 1.139 & 814 & 924 & 820 & 586 & 578 & 592 & 229 & 68 \\
\hline
\end{tabular}

$\mathrm{p}-/$ cifras preliminares

Fuente: Ministerio del Trabajo (2001). 
mente en el intento de otorgar a la mujer el tratamiento de sujeto de derecho y no de objeto de protección. Originalmente, el proyecto de dicha ley mantenía la orientación presente en la ley de 1936, ya que persistían las prohibiciones del trabajo nocturno y, en la regulación del cuidado infantil, se conservaba la idea de que la atención a la reproducción de la especie humana era una obligación natural de la mujer. La acción coordinada de parlamentarias de diversas tendencias políticas, unida al apoyo de periodistas feministas que adversaron la ideología del proyecto, logró su transformación, por lo cual finalmente se derogaron las disposiciones que prohibían el trabajo nocturno de la mujer y se garantizó que el trato legislativo se realice en igualdad de condiciones con el hombre. En la concepción actual, la protección de la maternidad se realiza en un contexto más vinculado con la familia que con la mujer y de allí que la anterior obligación de guarderías en cabeza de patronos que ocupen más 30 obreras se transformó en una obligación para el empleador que ocupe más de 20 trabajadores, sin importar su sexo.

En la regulación del trabajo femenino en la ley del trabajo hubo una casi total ausencia por parte del movimiento sindical, pues éste centró su acción en los temas de estabilidad y libertad sindical. La profundización de la protección legal y la promoción de la igualdad de oportunidades y de trato siguió un camino propio, y una serie de convenios internacionales y leyes fueron ratificados y dictadas en el último decenio del siglo $\mathrm{XX}$, cuya discusión e impulso se efectúa al margen del movimiento sindical.
Otros instrumentos legales que vieron la luz en los últimos años son la Convención relativa a la Eliminación de Todas las Formas de Discriminación contra la Mujer (CEDAW), la Ley de Igualdad de Oportunidades para la Mujer y la Ley sobre la Violencia contra la Mujer y la Familia, los cuales establecieron nuevos derechos, crearon órganos de protección y sancionaron conductas y hechos lesivos a la integridad de la mujer. La Constitución de 1999 profundizó las medidas en pro de la igualdad de oportunidades y de trato al obligar a garantizar la igualdad y equidad en el trabajo, y al establecer la acción positiva. Al mismo tiempo la Constitución avanzó en la protección de la mujer al consagrar el derecho a la seguridad social de las amas de casa y proteger el trabajo no remunerado en el hogar.

Nuevamente, la acción en pro de los derechos de la mujer estuvo en manos de mujeres vinculadas a partidos políticos con el apoyo de las universidades (Centro de Estudios de la Mujer de la Universidad Central de Venezuela), mientras que los sindicatos estuvieron casi ausentes del tema. Por tanto, la consagración de los derechos de la mujer se ha realizado fundamentalmente mediante el acceso que individualidades, vinculadas al sistema político han tenido en los órganos estatales. La acción ha estado más centrada en el Poder Legislativo y en el Ejecutivo que en la organización de las mismas mujeres, lo cual se corresponde con una dinámica propia al funcionamiento de la sociedad venezolana concentrada en la acción del Estado y, hasta época reciente, poco propensa al desarrollo de luchas dentro de la sociedad civil. Si bien, 
la constitución prevée una serie de herramientas que pudiese usar para avanzar en la igualdad de oportunidades y de trato, estos instrumentos han sido poco implementados, pues este tema todavía es asumido como lejano y ajeno a la realidad cotidiana de la mujer trabajadora. Por tal razón, no es de extrañar que la Defensoría de los Derechos de la Mujer sea poco conocida en el medio laboral, pues su radio de acción sobre la sociedad aún es incipiente.

\section{Las cláusulas de género presentes en las convenciones colectivas}

Para el análisis de los asuntos relativos a la mujer trabajadora y a las relaciones de género en las convenciones colectivas, en el marco del estudio que realizáramos para la OIT, se buscó detectar cláusulas en los siguientes temas: a) maternidad/ paternidad y cuidado infantil; b) condiciones de trabajo de la mujer y relaciones de género; c) equidad de género y no discriminación. Dentro de la metodología común establecida, los convenios colectivos a estudiar debían reunir las siguientes condiciones: a) los de mayor incidencia dentro de su sector específico y que marcasen tendencias dentro de la negociación colectiva, privilegiando, en los casos en que ello era posible, los convenios por rama; $b$ ) que fueran representativos de empresas o instituciones públicas y privadas y del sector industrial y de servicios. En el caso venezolano se estudió una muestra de 34 convenios colectivos, cuya composición se presenta en la Tabla 2.

Además se realizaron once entrevistas a dirigentes y miembros de directivas sindicales con el fin de recoger información sobre el comportamiento sindical en la materia, la presencia femenina en los procesos de negociación colectiva y los grados de cumplimiento e incumplimiento de las cláusulas estipuladas al respecto.

A continuación, previo al análisis específico de cada una de las cláusulas, hacemos dos tipos de referencias. En primer lugar, presentamos un listado de los principales problemas que inciden sobre las condiciones de trabajo del personal femenino, detectados a través de estudios en la materia ${ }^{4}$ o en nuestras propias investigaciones; esto con el fin de poder determinar más claramente los avances y los vacíos en la materia en nuestras convenciones colectivas. En segundo lugar, presentamos las regulaciones existentes por parte de nuestra legislación en la materia tratada, las cuales, en principio, deberían ser desarrolladas y ampliadas por la convención colectiva. No obstante, hay que anotar que, tanto por la información recogida en nuestro país como en los restantes de América Latina (Soares, 1998; Abramo, 2001) dado el grado de inobservancia de la normativa legal, su sola inclusión dentro de los contratos colectivos, dios Socioeconómicos (DIESSE, 1999), presenta una detallada relación de los principales problemas en cada área. 
Tabla 2

Composición de la muestra estudiada

\begin{tabular}{|c|c|c|c|c|c|c|}
\hline \multirow[t]{2}{*}{ Sector } & \multirow[t]{2}{*}{ Actividad } & \multicolumn{3}{|c|}{ Ámbito del convenio } & \multicolumn{2}{|c|}{ Sector } \\
\hline & & Rama & $\begin{array}{c}\text { Empresa o } \\
\text { institución } \\
\text { (Local) }\end{array}$ & $\begin{array}{c}\text { Empresa } \\
\text { o institución } \\
\text { (de escala } \\
\text { nacional) }\end{array}$ & Público & Privado \\
\hline \multirow[t]{4}{*}{ Industrial } & Siderurgia, metalurgia & & 5 & & 4 & 1 \\
\hline & Metalmecánica y automotriz & & 7 & & & 7 \\
\hline & $\begin{array}{l}\text { Petróleo, petroquímica, } \\
\text { química y farmacéutico. }\end{array}$ & 2 & 2 & 1 & 2 & 3 \\
\hline & Textil/confección y Calzado & 2 & & & & 2 \\
\hline \multirow[t]{4}{*}{ Servicios } & Servicios financieros & & & 4 & 2 & 2 \\
\hline & $\begin{array}{l}\text { Transporte, telecomuni- } \\
\text { caciones y electricidad }\end{array}$ & & 2 & 1 & 1 & 2 \\
\hline & Prensa & & 2 & & & 2 \\
\hline & Servicios públicos & 2 & 1 & 3 & 6 & \\
\hline
\end{tabular}

Fuente: Elaboración propia.

cumple un importante papel como garante para su cumplimiento.

\subsection{Cláusulas relativas}

\section{a la maternidad/paternidad}

$y$ al cuidado infantil

Los problemas que pueden presentarse en este renglón son los siguientes:

- Trabas para conceder los permisos para el control prenatal.

- Resistencia a transferir a las mujeres en caso de embarazo.

- Ausencia de provisión de la vestimenta adecuada.

- Dificultades para el reingreso de las mujeres después de la licencia por maternidad.

- Falta de local para amamantar y/o resistencia a conceder los tiempos necesarios.
- Falta de guarderías o incumplimiento de los pagos correspondientes.

- Imposibilidad del padre de acompañar a la madre y al recién nacido.

- Ausencia de estabilidad por paternidad reciente.

- Ausencia de protección a madres y padres adoptantes.

- Resistencia a conceder los permisos para atender hijos o familiares enfermos.

- Inexistencia de ayudas por parte de la empresa para la familia del trabajador.

Como podremos apreciar más adelante, los asuntos relativos a la maternidad son los que han recibido una mayor atención, tanto por parte de la legislación venezolana como de las convenciones colectivas, en comparación con el conjunto de problemas atinentes a la mujer trabajado- 
ra. Para su análisis, podemos distinguir los diferentes aspectos entre los referentes a: período prenatal y postnatal, lactancia y guarderías, licencia por hijo enfermo y compensaciones parentales.

\subsubsection{Período prenatal. Condi- ciones de trabajo durante el embarazo}

En el prenatal, las condiciones de trabajo de la mujer embarazada se pueden apreciar en la obtención de los permisos para el control prenatal, el tipo de tareas que debe hacer la trabajadora y la provisión de la vestimenta adecuada a su estado.

Respecto al control prenatal, si bien no hay disposición expresa legal que regule la obligatoriedad por parte del patrón de conceder permiso para llevarlo a cabo, está dentro, dadas sus características, del mismo régimen legal de los permisos remunerados por atención medica en general, pues es una contingencia médica cubierta por la Ley del Seguro Social Obligatorio. En cuanto al tipo de trabajo, la ley señala que la trabajadora está exenta de realizar cualquier actividad que por requerir esfuerzos físicos considerables o por otras circunstancias, sean capaces de producir el aborto o impedir el desarrollo normal del feto, sin que su negativa altere sus condiciones de trabajo (Art. 382 de la LOT). Un aspecto como el relativo a la dotación del vestuario adecuado a la condición de embarazo no aparece en la legislación. Lo relativo a la cobertura médica con ocasión del embarazo, lo que incluye atención durante el prenatal, el parto y el postnatal, está contemplado por la Ley del Seguro Social.
Las convenciones colectivas, por su parte, regulan poco las condiciones de trabajo de la mujer embarazada. Los permisos remunerados para el control prenatal se encuentran solamente en 8 convenios y no existen disposiciones que repitan o refuercen la obligatoriedad del cambio de tareas, o que estipulen lo del vestuario, excepto en uno de los convenios estudiados (el de la industria farmacéutica) donde existen cláusulas relativas a ambos asuntos.

Durante la vigencia de las convenciones colectivas se suelen celebrar acuerdos que pueden luego ser incorporados a aquellas o permanecer como tales, siendo de igual compromiso por las partes. Tal es el caso en el Metro de Caracas donde se estableció, mediante un acuerdo verbal a principios de los noventa, que, una vez que la trabajadora participa su condición de grávida, inmediatamente debe ser transferida del área operativa a la administrativa. En los otros casos estudiados, excepto en telecomunicaciones, textil/confección y calzado, la tradición es cambiar de puesto a la trabajadora si ésta lo solicita, en lo que fueron particularmente enfáticos los dirigentes sindicales entrevistados en las dos bancas. En los sectores donde existen áreas operativas, se nos dijo que la presencia de mujeres embarazadas no es propiamente bien recibida por parte de los propios compañeros de trabajo, sobre quienes repercute como sobrecargo de tareas; las mujeres que tienen continuos embarazos generan rechazo incluso por parte de las otras mujeres.

Las entrevistas en profundidad reportaron la existencia de condiciones ina- 
decuadas para la mujer embarazada: sillas incómodas, sitios poco aireados, instrumentos de trabajo poco adecuados. No obstante, los dirigentes sindicales no suelen recibir reclamos por ello y, aparentemente, no son situaciones que produzcan abortos o grave peligros para el embarazo. En cuanto al vestuario, en la mayoría de los casos, las trabajadoras deben abastecerse por su propia cuenta, pero por lo general no se les exige el uso de uniforme (lo que no exime que ella deba correr con el gasto de su propia ropa de trabajo).

Si bien la mayoría de los entrevistados no manifiestan preocupación por la ausencia de cláusulas relativas a la regulación de la salud de la mujer trabajadora durante el embarazo, en virtud de la escasas denuncias por incumplimiento de la ley en la materia, el hecho de que existan contratos que si las contemplan, es un indicio de que no siempre es un hecho garantizado. Pero, además, existen otro conjunto de derechos obtenidos a través de la negociación colectiva en otros países, que en nuestro caso no han sido contemplados, como por ejemplo, el recorte de la jornada de trabajo para la mujer embarazada (Soares, 1998). Respecto a la licencia para el control prenatal, tenemos otro dato adicional que nos permite comprender la escasa atención a este problema dentro de la convención colectiva: las estadísticas sanitarias reportan una muy baja asistencia de las mujeres a los controles prenatales, lo que dio origen a un programa social a principios de la década (cuando el 82\% no lo cumplía), justamente para atacar este problema; es decir, el control prenatal debe analizarse en un ámbito más amplio que la simple consagración legal y convencional de ese derecho. De ahí que, si no hay gran conciencia sobre la importancia del control prenatal y la mayor parte de las mujeres no lo practica, no es de extrañar que este no sea un tema expreso en la negociación colectiva.

\subsubsection{Período postnatal. Licencia por maternidad e inamovilidad}

Nuestra legislación establece que el tiempo de licencia prenatal es de seis semanas y el postnatal de doce, pero permite la acumulación de ambos permisos para después del parto. Durante ese período, su remuneración corre por cuenta del Instituto Venezolano de Seguros Sociales (IVSS). La trabajadora en estado de gravidez y hasta un año después del parto goza de estabilidad, norma muy cuestionada por parte importante del empresariado, a pesar de que pueden llevar a cabo el despido calificado. La licencia por adopción está prevista en la LOT, de manera que toda trabajadora que adopte un niño menor de tres años tiene derecho a diez semanas de permiso y goza, igualmente, de estabilidad hasta un año después de la adopción.

Respecto a los pagos durante la licencia por maternidad la investigación nos permitió descubrir un hecho interesante. El monto de la indemnización que paga el Seguro Social era, hasta 1991, del $66,6 \%$ del salario básico de la trabajadora. Como en 1990 se reformó la Ley Orgánica del Trabajo, en 1991 se adaptó la Ley del Seguro Social a los nuevos lapsos establecidos por aquella y, junto con ello, se incrementó el monto de la indem- 
nización que pagaba el IVSS, pasando del mencionado $66,6 \%$ del salario al $100 \%$ del salario norma 6 de la trabajadora. Antes de la reforma de la Ley del Seguro Social, la tendencia en las convenciones colectivas era estipular que el patrón se responsabilizaba por cubrir la parte del salario básico que no cubría el seguro, es decir, el 33,4\% restante. Una vez que la reforma estableció que el IVSS debía asumir el pago del salario normal o completo de la trabajadora, era de suponerse que las convenciones colectivas modificarían su cláusula al respecto, estableciendo, por ejemplo, que la parte que antes daba el patrono pasase a constituir una mejora del salario de la trabajadora durante la licencia maternal o que simplemente quedase eliminada. Sin embargo, pudimos informarnos que tanto el mismo IVSS como los patrones y sindicatos desconocen los cambios que al respecto se hicieron en la ley de 1991, de manera tal que el primero nunca ha pagado más del $66,6 \%$. Este hecho evidencia la poca importancia del tema de la mujer dentro de la negociación colectiva, porque en la práctica tiene implicaciones que se han pasado por alto por parte de todos los actores. Tiene implicaciones para los patronos, ya que están corriendo con un gasto que no les corresponde y tiene implicaciones para la trabajadora, ya que la posibilidad de recibir un salario por enci- ma del porcentaje que le otorga el IVSS queda dependiendo de los resultados de la negociación colectiva.

Aunque no todas las convenciones colectivas tienen cláusulas relativas a la licencia maternal, los sindicalistas fueron enfáticos en afirmar que es un régimen que se cumple sin problemas y que, por lo general, los empresarios dan los permisos correspondientes y siguen pagando a la trabajadora el salario básico, y cuando ésta recibe el cheque correspondiente por parte del IVSS, lo reembolsa a la empresa. No obstante, no se han percatado de que en las 9 convenciones colectivas que no existe disposición al respecto, así como en otras 11 que si la incluyen, la trabajadora está recibiendo un pago inferior a lo que legalmente le correspondería, que es el salario normal, tal como explicamos anteriormente. Las restantes 14 convenciones colectivas estudiadas establecen pagos por encima del salario básico y 3 de ellas incluso superan al salario normal. Concretamente, en las convenciones de telecomunicaciones, química y farmacéuticos, es donde el sindicato ha conquistado las mejores condiciones de pago durante la licencia maternal.

En lo que respecta a la duración de los permisos, si bien la mayoría repite los lapsos legales, 8 de las convenciones colectivas han logrado ampliarlos y en la electricidad llega a ser hasta de 18 días

5 Por salario básico se entiende el pago fijo que recibe el trabajador por la jornada ordinaria contratada.

6 Por salario normal se entiende el pago que recibe el trabajador como resultado de la remuneración básica más una serie de pagos como, por ejemplo, los de cesta tickets, bonos de asistencia y transporte, horas extras, entre otros. 
adicionales remunerados. En cuanto a la estabilidad, 3 convenios de rama repiten la normativa legal, lo cual se compadece con el hecho que son los que agrupan también a las medianas y pequeñas empresas, donde más se observan los incumplimientos.

En caso de aborto, el permiso solamente está contemplado en dos de los convenios, siempre y cuando, el embarazo supere los noventa días en uno de ellos y los ciento veinte días en el otro. En lo relativo a la licencia por adopción solamente se encontró en un convenio que repite la consagración legal de este derecho. En este tema la negociación colectiva podría avanzar estableciendo el derecho de permiso para el padre adoptante, no previsto en la legislación.

\subsubsection{Lactancia y guarderías}

La Ley Orgánica del Trabajo establece que, durante el período de lactancia, la mujer tendrá derecho a dos descansos diarios de media hora cada uno para amamantar a su hijo en la guardería respectiva. Si no hubiere guardería, los dos descansos previstos en este artículo serán de una hora cada uno, lo que supone dos horas diarias de permiso. El periodo de lactancia fue limitado hasta un máximo de seis meses después de ocurrido el parto. En cuanto a las guarderías, la LOT obliga a todo patrono que emplee más de 20 trabajadores de cualquier sexo a mantener una para que sus trabajadores puedan de- jar sus hijos durante la jornada de trabajo; este derecho está limitado a los trabajadores que devenguen menos de cinco salarios mínimos y cuyos hijos tengan hasta cinco años de edad. En caso de que el patrono opte por el pago del servicio a una institución privada, se estableció como monto obligatorio un máximo equivalente al $38 \%$ del salario mínimo. En cambio, si opta por el Programa de Hogares y Multihogares de Cuidado Diario, la determinación del costo queda a cargo de las negociaciones entre el patrono y la organización no gubernamental que se escoja dentro del Programa.

El derecho a la lactancia está poco presente en las convenciones colectivas, pues sólo lo contemplan 8 de las 34 revisadas. A la poca presencia del tema se le suma que 6 contratos repiten la ley y sólo 2 de ellos mejoran el derecho: el de la industria textil/confección que establece que el período de lactancia tendrá una duración de hasta seis meses continuos, contados a partir de la fecha en que se cumplan las doce semanas siguientes al parto ${ }^{7}$ y en el del Metro de Caracas donde se encuentra la mejor cláusula al respecto, pues, el tiempo de lactancia está ampliado a un año, e incluso se deja abierta la posibilidad de un tiempo superior, asunto que le significó una fuerte lucha al sindicato. En las convenciones restantes, en virtud de que la mayor parte de las mujeres se reincorporan al trabajo seis meses después de ocurrido el parto, por

$7 \quad$ En este convenio, esa es la única cláusula que supone una protección superior a los mínimos legales en el tema de la mujer, a pesar de ser un sector que emplea mayoritariamente mano de obra femenina. 
efecto de acumular el prenatal y juntarlo con el postnatal, más el tiempo de sus respectivas vacaciones, el derecho a la lactancia queda prácticamente sin efecto; el plazo establecido por la legislación constriñe, entonces, el periodo de la lactancia, a pesar de las indicaciones médicas que la prescriben por más tiempo

A través de las entrevistas, pudimos conocer que el ejercicio del derecho a la lactancia se ha trasformado, en la práctica, en una reducción de la jornada de trabajo de la mujer lactante, pues la mayoría de las mujeres no amamantan durante la jornada de trabajo, sino que usan las dos horas juntas al inicio o al final de la jornada. Esta forma de resolver el problema es el resultado del incumplimiento con las guarderías, como veremos a continuación, pues su existencia es lo único que puede garantizar el verdadero ejercicio del derecho a la lactancia.

La cláusula respecto a la guardería se encuentra en 14 de los 34 convenios revisados, repitiéndose en 9 de ellos la legislación vigente, sin especificar si se va a emplear el pago o la constitución de una guardería y en los otros 5 casos se desmejora la previsión legal, ya sea porque se especifica un pago inferior al contemplado, se reduce al período en el cual se tiene derecho o se restringe el beneficio al caso de las mujeres trabajadoras.

Las convenciones colectivas, al no especificar la forma en que se debe cumplir con la obligación, lo dejan a la discrecionalidad patronal, lo que se ha traducido simplemente en incumplimiento, tal como lo han reportado las estadísticas oficiales. Por tanto, las guarderías infantiles siguen siendo un tema pendiente en el sistema de relaciones de trabajo venezolano, pues el alto grado de inobservancia de la ley no ha sido objeto de acciones de la administración del trabajo y tampoco es causal de procedimiento de multas por parte de la inspectoría del trabajo, y pocos son los sindicatos que han hecho de esto un problema a confrontar.

\subsubsection{Licencia por paternidad}

No existe ninguna disposición legal en nuestro país respecto a la licencia paternal y sin embargo 26 de las convenciones colectivas la contemplan; es decir, ésta es una conquista fruto de la negociación y de la acción sindical. Sin embargo, en la mayoría de los casos el permiso es de un día y en 10 de los contratos estudiados el permiso es de tres o cinco días si el trabajador debe trasladarse lejos de su lugar de trabajo, por lo que el carácter del permiso refuerza la idea de que la responsabilidad del infante es exclusiva de la madre. En ninguna convención está contemplada la estabilidad para el padre después del nacimiento de su hijo, lo que sí existe en otros países (Abramo, Palenzuela y Pollack, 2000).

\subsubsection{Las licencias por hijo enfermo}

Los permisos (con o sin remuneración) para atender hijos enfermos son de origen convencional en Venezuela, pues no hay previsión legal sobre este aspecto. En tal sentido, su consagración en las convenciones colectivas es, sin lugar a dudas, una conquista del movimiento sindical.

Este tipo de licencia no suele estar restringida a los hijos, sino que abarca padres, hijos, cónyuge o persona con quien se haga vida marital e incluso, en 
ciertos convenios, los abuelos y otros parientes que dependan económicamente del trabajador. Estos permisos se encuentran contemplados en 7 de las convenciones colectivas estudiadas y su duración va desde uno hasta un máximo de diez días hábiles al año, con excepción de 2 convenios en los que no se fijan límites, sino que queda sujeto a los informes médicos.

Los permisos por enfermedad de familiares no son frecuentes en la contratación colectiva, pero haberlos encontrado en empresa publicas y privadas muy diferentes, es un buen indicio que se ha iniciado su consagración convencional y que se podría estar en un tránsito hacia un régimen contractual en torno al trabajador con responsabilidades familiares.

\subsubsection{Compensaciones familiares}

En las convenciones colectivas venezolanas existen un conjunto de cláusulas que establecen beneficios económicos por diferentes conceptos vinculados a la familia, las cuales son también de origen convencional. Sin embargo, es muy importante destacar que dichas compensaciones, a menos que se estipule lo contrario, no forman parte del salario. No obstante, los bajos salarios predominantes y la congelación de la parte del salario que tiene efectos sobre las prestaciones, condujo a utilizar la vía de las bonificaciones como forma de mejora del ingreso, lo que supuso un proceso de desalariza- ción, el cual fue limitado con la reforma de la LOT en 1997. Es por ello que, dentro de nuestro sistema de relaciones laborales, las denominadas cláusulas socio-económicas, dentro de las que están las compensaciones parentales, han sido, junto con todo lo relativo a los salarios, el tema privilegiado dentro de la negociación colectiva.

Los tipos de compensaciones que involucran a los hijos son diversos: prima por nacimiento, subsidio familiar (bono por hijo u otras modalidades), ayuda educacional (subsidio educativo, becas, servicios educativos, útiles escolares, ayuda por hijos excepcionales), seguro de salud y recreación (juguetes y recreación infantil).

El renglón de las compensaciones familiares es, largamente, el que reúne el mayor número de cláusulas en las convenciones colectivas respecto a los otros temas estudiados, pues, de un total de 275 cláusulas vinculadas a los asuntos considerados $^{8}$, suman 164 , lo que representa el $47 \%$ del conjunto. No obstante, excepto lo relativo al seguro de la salud, por lo general, las cantidades otorgadas por los diferentes causales son muy pequeñas y a veces incluso pírricas (en su mayoría están entre los 1.400 y los $25.000 \mathrm{Bs}$.). Aunque son beneficios en dinero que tienen un cierto peso para una población que recibe muy bajos salarios, denotan la tendencia de la negociación colectiva en nuestro país de enfatizar en los asuntos de carácter económico sobre

No en todos los casos representan cláusulas en sí mismas, porque hay casos en que una cláusula contiene diferentes renglones o beneficios, mientras que en otros casos éstos sí están discriminados. 
otros aspectos que podrían tener más relevancia y un mayor efecto a largo plazo.

\subsection{Cláusulas sobre las condiciones de trabajo}

En este renglón incluimos: salud ocupacional, condiciones de ingreso, ambiente y organización del trabajo, formación profesional y acoso sexual.

\subsubsection{Salud ocupacional}

El tipo de problemas que pueden presentarse en este renglón son los siguientes:

- Desconocimiento sobre la salud ocupacional y su relación con la salud reproductiva de ambos sexos.

- Desatención de las enfermedades típicamente femeninas.

- Desconocimiento de los problemas producidos por los períodos menstruales y falta de provisión de toallas higiénicas.

- Alta discrecionalidad empresarial para decidir sobre los riegos que pueden afectar a las trabajadoras.

En materia de salud ocupacional, la LOCYMAT señala que el trabajo deberá desarrollarse en condiciones adecuadas para preservar la capacidad física y mental de los trabajadores y apunta concretamente que ellas deben garantizar una protección adecuada a la mujer. Aparte de ello, no contiene disposiciones especificas relativas a salud ocupacional o enfermedades profesionales típicamente femeninas, pero no hay dudas que todas éstas están englobadas en la definición de la ley y que se les aplica el mismo régimen.

En las convenciones colectivas, las cláusulas relativas a la salud, cuando existen, tienen por lo general una redacción general, poco comprometedora y no existen normas que se refieran expresamente a la salud de la mujer, al tipo de tareas que desarrolla más comúnmente o que estén vinculadas a la atención de las enfermedades propias a su sexo, fuera de lo relacionado con su condición de madre. A pesar de que en la muestra de convenciones colectivas estudiadas hay una diversa representación de ramas productivas, en todas las cuales trabajan mujeres así sea en proporción muy baja, solamente en 1 convenio se encontró una mención a la atención médica a la mujer que fue en el de los empleados de la Universidad Central de Venezuela donde se contempla la garantía de un servicio de medicina preventiva que incluye las consultas de ginecología y el despistaje de cáncer.

\subsubsection{Condiciones de ingreso, ambiente y organización del trabajo}

Los aspectos sobre los cuales hay prácticamente una total ausencia en materia de regulación son los relativos a las condiciones de trabajo de la mujer, a pesar de ser el ámbito donde se presentan las situaciones más críticas ${ }^{9}$. Este es un tema poco desarrollado respecto a los trabajadores en general, rasgo común con el resto de la América Latina. "Se ob- 
serva la total ausencia de cláusulas relacionadas con el medio ambiente de trabajo, así como a los ritmos y organización de los puestos de trabajo. Vale señalar que esta ausencia existe no sólo en lo que se refiere a las condiciones y problemas específicos de las mujeres, sino también en relación con el conjunto de los trabajadores" (Abramo, 2001:67,68).

El tipo de problemas que pueden presentarse en este renglón son los siguientes:

- Preconceptos en relación a la contratación y en el acceso a las carreras:

- Dificultades de ingreso de las mujeres en puestos o carreras consideradas masculinas.

- Mayores exigencias a las mujeres que a los hombres para el acceso a puestos de trabajo.

- Preferencia por mujeres en los puestos más precarios.

- Mecanismos de promoción y de evaluación del desempeño "sexistas"

- Disminución de las posibilidades de ascenso profesional de las mujeres.

- Mayores exigencias de desempeño en el caso de las mujeres.

- Exigencia de disponibilidad fuera de la jornada de trabajo.

- Exigencia de movilidad geográfica.

- Condiciones salariales que desfavorecen a las mujeres

- Diferencias salariales entre puestos "masculinos" y "femeninos".

- Desvalorización de las habilidades consideradas femeninas.

- Fuerte peso de las horas extras dentro de las remuneraciones.

- Menosprecio por parte de las mujeres de sus propios atributos.
- Flexibilización del trabajo femenino

- Exclusión de las mujeres en los programas de nuevas tecnologías.

- Permanencia de las mujeres en los puestos de trabajo más atrasados.

- Externalización de los puestos femeninos.

- Mayor riesgo para las mujeres de ser despedidas en los momentos de crisis.

- Utilización de la mano de obra femenina como variable de ajuste de los costos de las empresas.

En ninguno de estos aspectos existe una regulación específica, ni en la legislación, ni en las convenciones colectivas estudiadas. La única cláusula que pudimos identificar donde se hace referencia al sexo femenino en materia de condiciones de trabajo fue una relativa a la distinción sobre la ropa de trabajo que debe ser suministrada a las mujeres, lo que aparece en 3 convenios colectivos. En lo referente a los salarios, en la ley -y las convenciones colectivas lo repiten- se establece la igualdad de salario por trabajo igual, pero, aparte de la dificultad de establecer dicha uniformidad cuando no son tareas idénticas, la diferencias salariales son básicamente la consecuencia de la discriminación previa en la adjudicación del puesto de trabajo.

\subsubsection{Formación profesional}

Los problemas más importantes que pueden presentarse en este renglón derivan de la discriminación en la formación profesional:

- Poco acceso de las mujeres a los cursos de formación profesional y a los 
programas de calificación y reentrenamiento de las empresas.

- Programas de formación fuera del horario de trabajo.

- Restricción de la formación a las mu jeres, principalmente en áreas consideradas femeninas.

Desde el punto de vista legislativo, en materia de formación profesional sólo se puede mencionar la obligación prevista en la Ley de Igualdad de Oportunidades para la Mujer que establece que el Estado y el sector empresarial deberán crear centros de adiestramiento para la superación profesional de la mujer (Art. 39). Esta obligación perfectamente podría ser desarrollada en las instancias de diálogo social o en la negociación colectiva.

En los contratos revisados, se encontraron un número importante de cláusulas que se refieren a la capacitación profesional, pero no solamente ninguna de ellas hace mención a la mujer, sino que, además, todas son sumamente generales, a manera de declaración de intenciones sobre la necesidad de apoyar y favorecer la formación de los trabajadores, sin establecer compromisos específicos. Es decir, asuntos como la regulación de la capacitación dentro de la jornada de trabajo o la inclusión de porcentajes de mujeres dentro de los beneficiarios, problemas que, de acuerdo a las entrevistas, restringen la incorporación de las mujeres, están totalmente ausentes.

\subsubsection{Acoso sexual}

Este problema se puede expresar en:

- Presión física y sicológica sobre mujeres u hombres.
- Exigencia de concesión de favores sexuales para preservar el empleo.

- Prejuicios para encarar los problemas de acoso sexual.

El Reglamento de la Ley Orgánica del Trabajo regula el acoso sexual como una expresión de discriminación inconstitucional y lo considera causal de retiro justificado. Además, el acoso sexual en el trabajo fue considerado un delito y los patronos pueden ser objeto de multas si no toman todas las medidas necesarias para evitarlo.

En ningún convenio hay una cláusula dirigida a atacar el problema del acoso sexual. Sin embargo, todos los entrevistados coincidieron en considerar que es un problema muy presente en sus respectivos lugares de trabajo.

Ante la pregunta acerca de si sería conveniente introducir una cláusula sobre la materia, los entrevistados respondieron con escepticismo, pues consideraron que es un problema muy complejo, de difícil demostración y que además tal cláusula no sería garantía de nada, como no lo es la existencia de una legislación al respecto. En síntesis, el problema existe con una cierta magnitud, todos lo ven con mayor o menor preocupación en el momento de abordarlo, pero no es un problema frente al cual el sindicato se sienta protagonista para intervenir frente a él. Todavía es percibido bien sea desde una perspectiva claramente machista que le adjudica la responsabilidad a la mujer, como un problema del ámbito de lo privado, o como parte de un juego de complicidades.

\subsection{Equidad de género}

En muchos de los aspectos anteriormente tratados se evidencia la desigualdad 
de oportunidades, pero hay otros ámbitos de la vida laboral que también expresan la existencia de discriminación en función del sexo, edad, raza, estado civil, apariencia personal o condición física.

La legislación establece varios principios para lograr la igualdad de oportunidades y de trato en las condiciones de trabajo con prohibición expresa de todo tipo de discriminación. Estos principios abren un amplio campo para la toma de medidas de acción positiva en favor de la mujer. Las directrices legales señalan objetivos a alcanzar, cuya concreción puede ser determinada por la negociación colectiva, la cual ha iniciado tímidamente ese camino.

Un total de 7 convenios se refieren al tema, la mayoría hace referencia al trato equitativo, pero en 3 se refieren específicamente a la no discriminación. Las cláusulas que tocan el tema lo hacen de manera muy similar a algunas declaraciones legales y, en términos muy generales, señalan la necesidad de adelantar acciones que garanticen un trato digno a los trabajadores por parte de sus superiores; es decir, están hechas con la intención de promover un ambiente de relaciones laborales más democrático, eliminando prácticas autoritarias y discrecionales en el manejo del personal.

Las cláusulas sobre equidad de género y no discriminación en las convenciones colectivas son de reciente data. El hecho de su aparición, aunque sea de forma tan general, representa de por sí una conquista, porque de esa manera se evidencia una valoración del asunto y aportan un marco para responder frente a situaciones de diversa naturaleza.

\section{Los temas de mayor presencia en las convenciones colectivas}

Las contingencias con ocasión a la maternidad ocupan un lugar preponderante en las convenciones colectivas, sólo superado por las compensaciones parentales en cantidad de cláusulas, pero no en contenido y significado de la regulación. Estratégicamente, tiene mayor peso una cláusula que aumente los pre y postnatales o que establezca la licencia de paternidad, que la de juguetes de fin de año. De ahí, que las ampliaciones en las licencias pre y post natal y los pagos con ocasión de éstas, las licencias por paternidad, las licencias por hijo enfermo, los pagos por guardería, son más indicativos de una preocupación en torno a la maternidad como aspecto central de la regulación convencional del trabajo desde una perspectiva de género.

La regulación de la licencia de maternidad cuenta con cierto arraigo en la negociación colectiva y son cláusulas de pacífica aceptación desde hace muchos años. El tema de la protección de la maternidad estuvo en el tapete público a inicios de los noventa con la promulgación de la Ley Orgánica del Trabajo; los primeros años de esa década los sindicalistas se preocuparon de presionar por la introducción en sus respectivas convenciones colectivas de cláusulas relativas a los nuevos derechos que les daba la ley y por garantizar que el patrono continuase asumiendo parte del costo salarial de la trabajadora en reposo. Pero, más que en la ampliación de los plazos de la licencia, la principal resistencia de los patronos estu- 
vo en la extensión de la inamovilidad hasta un año después del parto, amenazando que con ello se dificultaría la contratación de mujeres, ya que eso les resta flexibilidad en el manejo del volumen de su personal. A partir de entonces, se consolidó una matriz de opinión acerca de los costos excesivos que provoca el régimen de maternidad.

Después de esto, el tema ha adquirido gran invisibilidad, pero el hecho de que estuviese en la agenda pública de esos años no significó que todo el régimen protector aprobado fuese conocido y menos que tuviese aplicación. En la protección a la maternidad la principal violación proviene del propio Estado (del IVSS, tal como reseñásemos anteriormente). Vale la pena preguntarse si hubiese ocurrido lo mismo en caso de accidentes profesionales, que afectan más a los hombres que a las mujeres. ¿Los sindicatos de la siderúrgica o del petróleo tampoco se habrían enterado de la reforma? ¿Los trabajadores se conformarían con recibir salario básico en vez de salario normal? El hecho de que el Seguro Social no aplique la ley y que nadie le reclame no puede ser explicado simplemente por la situación de insolvencia y reestructuración crónica que vive la seguridad social en el país, sino que es un ejemplo más de la dificultades que enfrentan las mujeres para conocer y para hacer valer sus derechos.

Menor atención que a la licencia por maternidad se le ha prestado a la salud de la mujer embarazada. Para los dirigentes sindicales, aún cuando no existe la garantía de los otros aspectos, se aduce, por lo general, que se cumple en la práctica. No obstante, el hecho que algu- nos de esos aspectos estén estipulados en las convenciones colectivas y otros no, es muestra de la escasa atención frente a estos últimos, más aún cuando parte de la normativa al respecto no es tan clara o indiscutible como lo es la licencia por maternidad. No obstante, la licencia para el control prenatal no ha sido dejada a la discrecionalidad patronal en diversos sectores y en algunos casi opuestos, pues está contemplada en convenios que responden a sistemas de relaciones laborales muy disímiles. De allí, que en unos casos, tales cláusulas son expresión de una tendencia a la formalización y en los otros requisito para hacer valer un derecho no siempre reconocido.

Mas allá de la maternidad y de la familia, poco es lo que se puede encontrar en relación con la mujer. Las cláusulas son redactadas teniendo como norte la imagen masculina, aparte de que a menudo ni siquiera el lenguaje reconoce las diferencias de género. Para los mismos sindicalistas, las particularidades que representa la mujer se agotan en el hecho de la maternidad y solamente un sindicalista del sexo masculino manifestó consideraciones específicas acerca de las diferencias que supone la condición femenina frente al trabajo y sobre la discriminación soterrada que se manifiesta en la selección de los ascensos, de los integrantes de los cursos de capacitación, entre otras. Es decir, son temas que han alcanzado muy poca visibilidad en la práctica sindical y en la negociación colectiva.

La equidad de género aparece en los contratos en cláusulas genéricas similares a algunas declaraciones legales $y$, en muchos casos, en un contexto desti- 
nado a garantizar un trato digno y respetuoso a los trabajadores por parte de sus superiores. Sin embargo, el sólo hecho de que comience en los contratos a hablarse de respeto e igualdad, indica que se ha iniciado el tránsito hacia la regulación convencional de la garantía constitucional y legal de la no discriminación en el puesto de trabajo por razones de sexo.

\section{El liderazgo del sector público en la negociación colectiva}

Partiendo de que la temática sobre género ha avanzado relativamente poco en la convención colectiva venezolana, la investigación permitió corroborar la pervivencia de la tendencia histórica de que es en el sector público donde la negociación colectiva ha logrado obtener las mejores condiciones de trabajo. Este hecho puede verse como una expresión más de la segmentación del mercado de trabajo, pues los grados de protección social que gozan los trabajadores no sólo varían por la ubicación en el sector formal o informal y dentro de éste por los que gozan de negociación colectiva y los que son considerados independientes o que pertenecen a empresas no sindicalizadas, sino además varía entre los que pertenecen al sector público y al sector privado, pues, para quienes gozan de negociación colectiva, los beneficios en cuanto a estabilidad, seguridad social, tiempo de trabajo, utilidades, los beneficios son mayores en el primero que en el segundo. La estabilidad legal y convencional que se goza en el sector público marca la gran diferencia, pues la seguridad en el puesto de trabajo permite avanzar en la búsqueda de nuevos y mayores beneficios.
En los temas estudiados en esta investigación, la consagración en el sector público y el cumplimiento de lo estipulado es mayor tanto en cantidad como en calidad, pues son superiores en su contenido. Las ventajas observadas en el sector público se dan en los diferentes aspectos analizados en relación con la maternidad: en primer lugar, los permisos por maternidad son respetados y pagados con la remuneración total; en segundo lugar, la cobertura médica del embarazo y de la familia se realiza en su gran mayoría mediante pólizas privadas de salud; en tercer lugar, en la obligación de guardería, el sector que reportó mayor cumplimiento fue la administración pública centralizada, ya sea porque está pagando el $38 \%$ del salario mínimo o porque cuenta con guarderías o preescolares propios. Pero además, aún cuando no exista alguna cláusula en particular, en la función pública no existe la rigidez o el autoritarismo en el manejo de las relaciones de trabajo que suele presentarse en el sector privado. Al contrario, las relaciones de trabajo se desarrollan con apego a la institucionalidad laboral y en el tema de la familia existe una larga tradición de permisos para todo lo relacionado con el cuidado de hijos. La estabilidad absoluta en el cargo es un elemento que está muy presente en la conciencia del funcionario público, lo que posibilita incluso enfrentar y desafiar a sus superiores jerárquicos. Por ello, no es aventurado sostener que, si se incorporan al análisis las prácticas de la función pública no recogidas en sus convenios, los derechos alcanzados son significativamente superiores.

La consagración de un régimen mas beneficioso en el sector público per- 
mite, por tanto, que las mujeres que prestan sus servicios en él gocen de condiciones de trabajo superiores a las de sus pares con negociación colectiva en el sector privado. La mayor presencia de asalariadas en el sector público, con condiciones de trabajo que permiten compatibilizar las responsabilidades laborales con las familiares, sitúan la discusión de la equidad de género en un contexto muy diferente al que pueda darse en el sector privado, aunque paradójicamente, es en el primero donde la brecha de remuneración entre hombres y mujeres es más marcada (Iranzo y Richter, 2002a). De ahí, que la discusión en el sector público pudiese avanzar ya no centrada en el cumplimiento del régimen protector de la maternidad o en la consagración de condiciones especiales que permitan compatibilizar el desarrollo profesional y las responsabilidades familiares, sino justamente en el tema central de la discriminación por género: las diferencias salariales y el ascenso profesional. Este camino no ha sido ni siquiera visualizado por los sindicatos del sector público y es un reto pendiente en su agenda, sobre todo, por la riqueza del tema y las potencialidades que tiene para dar el vuelco a una negociación colectiva anquilosada y centrada en temas salariales de carácter general, que le quitan legitimidad no sólo frente a sus bases, cuando los aumentos finalmente se logran por vía de decretos legislativos, sino también frente a la sociedad en su conjunto, que visualiza al sindicalismo simplemente como instancia reivindicativa sectorial y no como promotora de la democratización de la sociedad en su conjunto.

\section{Las diferencias por sector productivo}

Aparte de los convenios en el sector público, las convenciones que presentan más y mejores cláusulas están dentro del sector industrial. Esto ocurre con convenios que cubren mayoritariamente mano de obra masculina, como es el caso de petróleos, química y metalurgia, como en otros donde predomina la mano de obra femenina, como es el farmacéutico. La diferencia entre unos y otros se presenta en la cantidad y en los tipos de beneficios, por ejemplo, la metalúrgica estatal se concentra en los beneficios con ocasión de la maternidad, mientras que el sector farmacéutico va más allá, creando un marco regulatorio más amplio. Los convenios estudiados en estos sectores tienen como rasgo común la presencia de un sindicalismo relativamente fuerte $y$ con una larga experiencia. Esto podría explicar que, habiendo logrado las conquistas de los asuntos más elementales, hayan podido trascender hacia otros aspectos. En estos casos pareciera haber el indicio de un cambio en la centralidad de los beneficios no salariales, en tanto en estos convenios, las cláusulas sindicales y los aportes para actividades recreativas han perdido peso, reforzándose los beneficios familiares, tendencia que puede considerarse la expresión del inicio de un régimen convencional de protección del trabajador con responsabilidades, dentro del cual podría estar comenzando a cobrar fuerza también los beneficios particularmente referidos a las mujeres.

La importancia de las características del sindicato podría verse reforzada 
al observar la convención colectiva por rama de un sector como el de textil /confección, pues a pesar de amparar a una alta población femenina, la mayoría de sus cláusulas no garantizan sino los mínimos de la legislación, lo que se corresponde con un sindicalismo muy débil que debe representar una miríada de pequeñas y medianas empresas. No obstante, hay otro sector con un sindicalismo fuerte, donde predominan las empresas de mediano tamaño, pero cuyas convenciones colectivas no gozan de las características de las mencionadas más arriba, que es la industria automotriz. Pero este sector tiene en común con el de textil/confección que viene atravesando una larga crisis desde hace más de una década, lo que ha contribuido a reforzar la tendencia sindical a concentrarse en la preservación del empleo y del salario. Es decir, son otros factores los que están incidiendo en la posibilidad de desarrollar los contenidos de la convención colectiva.

Habiendo podido observar a través de las conversaciones sostenidas con los sindicalistas que no existe en ninguno de los sectores estudiados una expresión social cristalizada que tenga como norte las luchas de género, más allá de ciertas individualidades, las diferencias entre unos y otros convenios parecen fundarse en los mismos factores que determinan el alcance de la negociación colectiva en su conjunto, como son el grado de fuerza y desarrollo del movimiento sindical, pero también el nivel de institucionalización de las relaciones obrero patronales, el tamaño de la empresa y la situación económica del sector, para mencionar los más relevantes.

\section{La presencia de la legislación y los avances de la negociación colectiva}

En el estudio de las diferentes convenciones colectivas pudimos observar como hay cláusulas que se limitan ha reproducir la legislación laboral, incluso remitiéndose directamente a ella. Para los sindicalistas esa es la única forma de asegurar que los trabajadores, incluso los delegados, estén al tanto de cuáles son sus derechos, ya que son muy raros los que conocen toda la legislación en la materia (que, por lo demás, está diseminada en varios instrumentos) $y$, por tanto, tener las regulaciones más importantes dentro de la convención colectiva es a su vez una forma de garantizar la exigencia de su cumplimiento. Esto incluso fue planteado a los patronos, ya que muchos de los pertenecientes a medianas y pequeñas empresas desconocen la misma legislación. De esa manera, además se estaría asumiendo una única interpretación, impidiendo futuros malos entendidos. También se adujo que una vez que la cláusula está incluida en el contrato es más fácil introducirle modificaciones y obtener mejoras en el futuro.

La negociación colectiva ha introducido una serie de beneficios que no tienen consagración legal, siendo sin lugar a dudas un avance en la protección, sobre todo, de la familia, lo que allana el camino para la consagración legal de nuevos derechos, pues es costumbre en el país que, cuando una institución se arraiga en las convenciones colectivas, su paso a la ley genera menos polémicas. De hecho, ha sido el argumento utilizado 
para justificar la inclusión de nuevos derechos en la legislación laboral.

Lo más trascendente de las cláusulas al respecto es que desvinculan la protección de la maternidad exclusivamente de la madre al consagrar una serie de derechos a favor del padre, tales como la licencia por paternidad. Las compensaciones parentales presentes en la mayoría de las convenciones también reflejan la importancia que la protección de la familia ocupa en las relaciones de trabajo, aunque no se puede pasar por alto que la inclusión de tales cláusulas ha servido como mecanismo para compensar los bajos salarios y disminuir los efectos del salario sobre el resto de pagos con ocasión del trabajo. No obstante, no puede menospreciarse que la vía para ello haya sido la familia y no la recreación, deportes o cláusulas sindicales que también cumplen efectos similares en la desalarización.

Entre las cláusulas introducidas sobre la materia de género, si bien hay repeticiones de la normativa legal, son más las que incorporan mejoras. Algunas cláusulas son innovaciones como las de paternidad, licencia por hijo o familiar enfermo o compensaciones parentales. También la cláusula sobre permiso prenatal, en la medida en que no existe una regulación directa y explícita en la materia, es una innovación de la convención colectiva. En lo que respecta al tema de la maternidad se observan avances entre convención y legislación en cuanto a los lapsos de duración del permiso y en cuanto a la remuneración (haciendo la salvedad del incumplimiento de base del IVSS). También hay cláusulas sobre la lactancia que introducen mejoras. En otros aspectos, como licencia por adop- ción o equidad de género y no discriminación, no hay cláusulas que mejoren lo estipulado, sino que reconocen las que existen. Respecto a legislación, el asunto peor tratado es el de las guarderías, pues incluso hay cláusulas que la desmejoran, único asunto en que se observa tal fenómeno. Los asuntos sobre los que se observa un enorme vacío son todos los relativos a las condiciones de ingreso, ambiente y organización del trabajo, donde está incluido el tema de los salarios, los ascensos, la formación profesional y el acoso sexual, pues no se encontró ninguna cláusula dirigida a corregir los graves problemas existentes.

A pesar de las insuficiencias, en líneas generales, la convención colectiva se está convirtiendo en un instrumento de superación de los términos estipulados legalmente. Los logros en algunas convenciones colectivas, permiten apreciar como existe todavía un amplio espacio de mejoras posibles para la mayor parte de las convenciones colectivas sobre los cuales deberán actuar los sindicatos, muchos de los cuales a menudo se dan por satisfechos con lo establecido por la ley.

\section{Niveles de cumplimiento}

La incorporación de cláusulas sobre género y su cumplimiento no puede desligarse del nivel general de acatamiento de la legislación laboral, del grado de institucionalidad de las relaciones laborales en cada sector en particular, del tipo y fuerza del sindicalismo y, por supuesto, del estado general de la convención colectiva en el país.

La tendencia a centrar los reclamos en los incumplimientos más graves y fla- 
grantes hay que analizarla tomando en cuenta que estamos frente a un medio laboral donde las infracciones por parte de los patronos son un hecho común. La presencia sindical en el sitio de trabajo es un elemento clave para garantizar el respeto de la convención, siempre que no se trate de sindicatos patronales o de protección. En sectores como el financiero, por ejemplo, el cual cuenta con sindicatos en todas las agencias bancarias, no siempre está asegurada la defensa clasista de los trabajadores: en la banca pública, las relaciones clientelares atraviesan la acción sindical, y, en la banca privada, los sindicatos han sido tradicionalmente muy afectos a los discursos patronales sobre la superación individual dentro de la empresa. Este mismo problema se presenta en los convenios por rama de industria, los cuales además enfrentan la ausencia de sindicatos en las pequeñas y medianas empresas, por lo que no es de extrañar que éstos sean los sectores en los cuales se reporta un mayor incumplimiento y ello ocurre también en los temas vinculados a la mujer.

Sin embargo, en el tema de la maternidad pareciera prevalecer cierto grado de institucionalidad en torno al régimen protector y no está entre los aspectos que los sindicatos denuncian como los de mayores incumplimientos patronales. Esto no puede desvincularse de la jurisprudencia administrativa y judicial que fue consolidando el régimen tuitivo de la maternidad. Esta acción consistente de la jurisprudencia nacional reforzó la creencia popular de que las mujeres embarazadas son intocables hasta un año después del parto. Otros asuntos vinculados a la maternidad, como los permisos para los controles prenatales, los cambios en los puestos de trabajo, las licencias para atención de hijo enfermo, tienen diversos grados de cumplimiento y ello está estrechamente vinculado con la institucionalización de las relaciones de trabajo en la empresa y sus características internas (modernización y ubicación en el sector estructurado de la economía). Así, en una empresa con condiciones de trabajo estables, con organización interna con criterios institucionales, los permisos y licencias, con ocasión del embarazo y de la maternidad, se desarrollan en un medio más favorable que en una empresa con poca modernización tecnológica y organizacional. En las otras empresas, es la presencia de dirigentes o delegados sindicales informados y formados, lo único que puede realmente garantizar el cumplimiento de la convención colectiva en estos y otros ámbitos.

El área donde se pudo constatar el mayor incumplimiento es el de las guarderías, siendo un campo en el que ha avanzado muy poco la negociación colectiva. La ley deja abierto un amplio espectro de posibilidades que bien podrían ser precisadas por el convenio colectivo para garantizar un mayor cumplimiento. Su no existencia repercute a su vez en la posibilidad de ejercer el derecho a la lactancia, estimulando así su conversión en una reducción de la jornada de trabajo para la madre, lo que desvirtúa su objetivo, que era garantizar al infante el beneficio de la leche materna. Pero los mayores problemas se concentran en el área que es menos visible y a los cuales la convención colectiva no les ha prestado ninguna atención: condiciones y medio ambiente del trabajo femenino. 
De cualquier manera, los temas vinculados al género no están hoy en día en la agenda de nuevas peticiones, ni en el discurso de los dirigentes, ni en las preocupaciones de la base. Esto se pudo recoger tanto a través del análisis de los proyectos presentado por el sindicato en la mesa de negociaciones, dentro de los que en muy raros casos se observaron peticiones diferentes a los asuntos que luego quedaron incluidos en las convenciones colectivas, como a través de los mismos entrevistados, quienes reconocen que, en aquellos casos que hubo modificaciones 0 rechazos, no se hizo de ello un problema de honor, porque la atención fundamental estaba situada en otros renglones.

\section{A modo de conclusión}

Los rasgos de las convenciones colectivas venezolanas no son más que la cristalización de los problemas que desarrollásemos en nuestro artículo precedente (Iranzo y Richter, 2002a). El predominio de la cultura masculina en el ámbito del poder y en todos los espacios de la lucha política, la dificultad de la mujer para participar en esos espacios, pero además para asumir sus propias necesidades como legítimas en tanto de carácter colectivo que trasciende el terreno de lo privado y su propia dificultad para traducir esas necesidades en demandas concretas posible de ser plasmadas en los pliegos de peticiones, son parte importante de los factores que nos explican los vacíos de las convenciones colectivas en materia de género.

Es larga la lista de los asuntos en los diferentes renglones atinentes al trabajo que no han sido incorporados como reivindicaciones en los convenios colectivos y ni siquiera en los pliegos de peticiones. Los temas propios de la mujer no surgen en las asambleas o consultas sobre el posible contenido del convenio y las pocas mujeres que participan en la mesa de negociaciones tampoco introducen las cuestiones relativas a la promoción de la igualdad de oportunidades y de trato. Por los temas presentados en las asambleas, en los pliegos de peticiones, por la regulación que se encuentra en las convenciones colectivas y por las informaciones obtenidas en las entrevistas, pareciera que las mujeres no tienen necesidades especiales en su trabajo, que son tratadas sin discriminación y que enfrentan los mismos problemas que los hombres. De acuerdo a los sindicalistas, por lo general, el régimen de la maternidad se respeta, los permisos para cuidar hijos enfermos rara vez son negados $y$ existen una serie de beneficios a favor de la familia sobre los cuales se suelen sentir los sindicalistas orgullosos. ¿Este cuadro tan favorable es real? ¿la mujer venezolana goza de la equidad en materia de género?

Pero la otra cara de la moneda, que también surge en las entrevistas, es que las mujeres padecen problemas muy específicos: ocupan los puestos peor remunerados; tienen muchas dificultades para ascender e incluso en sectores donde son mayoritarias, predominan los jefes y supervisores hombres; que la composición de los trabajadores subcontratados suele ser predominantemente femenina; que sufren situaciones de acoso sexual con escasa posibilidad de solución. Además, casi todos los sindicalistas hombres hablan, en un tono que va de la admiración a 
la conmiseración, de la doble jornada de trabajo que la mujer debe ejercer. En líneas generales, se presenta un panorama muy similar al diagnosticado en los otros países de la región (Arango, 1999).

Tanto los dirigentes sindicales como los empresarios del sexo masculino, consideran más responsables a las mujeres en el puesto de trabajo, más disciplinadas y hasta más comprometidas con su trabajo. Faltan menos, trabajan más y ganan menos, pero no se quejan y sean muchas o pocas las que ocupan cargos directivos, ella mismas no colocan sus propios problemas en la mesa de negociaciones; todo indica que les cuesta tomar conciencia de sus problemas particulares ${ }^{10}$.

Los problemas de la mujer en el puesto de trabajo existen, están ahí, pero formando parte de una agenda oculta que cuesta incluso a la propia mujer asumir. Sus problemas no pueden desvincularse de la conciencia de género pues de ella depende la solución de una situación que permanece poco visible y que ocurre cotidianamente. Pero tampoco pueden desvincularse del contexto actual de la negociación colectiva y del país en general. Las presiones por asuntos no estrechamente vinculados a violaciones elementales de condiciones de trabajo pueden parecer exóticas en un medio laboral que no cuenta mayoritariamente con protección social, y por ende no generar mayo- res solidaridades o repercusiones sociales. Las trabajadoras que están cubiertas por la negociación colectiva son casi unas privilegiadas entre sus pares, desarrollan su trabajo en un ambiente de relativa protección, por lo que, ante la desprotección absoluta que las rodea y el descenso del salario en su conjunto, sus problemas particulares tienden a pasar desapercibidos. Por tanto, no es posible analizar la incorporación de los temas de género en la negociación colectiva sin tener presente las condiciones mismas por las que ésta ha atravesado. "La debilidad de los temas de género no es un problema específico, sino que refleja la debilidad general de los procesos de negociación colectiva" (Abramo, 2001:75). Esta situación, amén de la falta de capacitación de los mismos dirigentes sindicales, desincentiva la inclusión de nuevos temas en la negociación, bien sea los relativos al género o a la reestructuración productiva producida durante el período.

Una situación similar es la que se ha vivido en el resto de la América Latina, incluido el caso del Brasil: "Según el DIEESE (1994:64), en los años ochenta, en el marco del proceso de transición democrática y de reorganización del movimiento sindical se logró una importante ampliación de los espacios de negociación colectiva, así como de sus contenidos y resultados. En los años noventa, a su vez, en el

10 En un taller con mujeres sindicalistas organizado por el INAESIN y la OIT, se produjo una fuerte discusión cuando les hicimos algunas de estas consideraciones. Plantearon que ellas son la demostración de que es perfectamente posible llegar a ser dirigentes, simplemente hay que esforzarse, e incluso una de ellas señaló: "Yo soy albañil y no tengo nada que recriminarles a los hombres, por el contrario, debo agradecerles que, a pesar de ser mujer, me hayan permitido ejercer mi profesión". 
contexto de la apertura comercial y de la reestructuración productiva, se observa une estancamiento de las conquistas de los años ochenta, así como una fuerte embestida patronal en contra de los derechos anteriormente adquiridos".

El sindicalismo ha pasado por épocas difíciles en los últimos años en Venezuela. La crisis política le ha permitido recuperar espacios de legitimidad ante la sociedad, pero los ha perdido en el mundo del trabajo. La principal expresión de sus dificultades para cumplir una de sus misiones más elementales, en su rol de representante del trabajo en el sistema de relaciones laborales, es el estado actual de la negociación colectiva: cobertura cada vez más limitada y reducida a temas netamente salariales, en los cuales tampoco está incidiendo en forma preponderante $y$, en muchas ocasiones, el convenio colectivo simplemente reproduce una decisión tomada por el empleador.

No obstante, el tema de la dignidad y respeto en el puesto de trabajo ha comenzado a aparecer tímidamente en las convenciones colectivas, y tal vez sea el primer reflejo de la entrada en la agenda de las negociaciones del tema de las condiciones de trabajo de la mujer. La visibilidad de sus problemas es todavía incipiente y todavía ocupa un lugar secundario dentro de la negociación colectiva. Dentro de todas las dificultades y a pesar de la fuerza de una cultura donde prevalece lo masculino, hay convenciones colectivas que han atendido algunos de esos problemas y ellas podrían servir de efecto de demostración de lo que es posible llevar a cabo.
Dentro del rescate de la negociación colectiva y en la ampliación de su cobertura, los temas de equidad de género pudiesen jugar un rol activador. El tema de género tiene muy importantes potencialidades para transformar el sitio de trabajo y reforzar el poder sindical, constituyendo una buen razón para sentarse en la mesa de negociaciones en momentos en que, a causa de la profunda crisis, lo netamente salarial tiene limitaciones severas y se revela como insuficiente para rescatar los espacios de negociación perdidos. Pero para ello se requiere tomar conciencia de que la democratización del sitio de trabajo pasa por garantizar la igualdad de trato y de oportunidades para ambos sexos.

\section{Bibliografía Citada}

Abramo. Laís (1998), "Um loar de genero. Visibilizando precarizacoes ao longo das cadeias produtivas" en Lais Abramo y Alicia Rangel: Genero e trabalho na sociología latino-americana. Ed. ALAST/SERT, Sao Paulo.

Abramo. Laís (2001), Negociación colectiva y equidad de género en América Latina: nuevos desafíos para la acción sindical" en el Dossier: El sindicalismo latinoamericano en el marco de la globalización: crisis y retos a comienzos de siglo. Revista Cuadernos del CENDES, Año 18, segunda época, mayoagosto, Caracas.

Abramo, Lais, Valenzuela, María Elena y Pollack, Molly (2000), Equidad de género en el mundo del trabajo en América Latina. Avances y desafíos cinco años después de Beijing. OIT, $\mathrm{n}^{\circ} 130$, Lima.

Arango, Luz Gabriela (1999), "Género, globalización y reestructuración productiva" 
en Luz Gabriela Aranfo y Carmen Marina López: Globalización, apertura económica y relaciones industriales en América Latina. Facultad de Ciencias Humanas UN, Bogotá.

Constitución de la República de 1999.

De la Garza, Enrique (2000), "Fin del trabajo o trabajo sin fin" en Enrique de la Garza (coord.): Tratado Latinoamericano de Sociología del Trabajo. Fondo de Cultura Económica, México.

DIESSE (1999), Mapa das questoes de gênero. CUT, CGT, Forza Sindical y DIESSE, Sao Paulo.

Dombois, Rainer (1999), Tendencias en las transformaciones de las relaciones laborales en América Latina. Los casos de Brasil, Colombia y México" en Luz Gabriela Arango y Carmen Marina López: Globalización, apertura económica y relaciones industriales en América Latina. Facultad de Ciencias Humanas UN/Colección CES, Bogotá.

Instituto Nacional de Estadística: Encuesta de Hogares por muestreo.

Iranzo, Consuelo y Richter, Jacqueline (2002a), "El espacio femenino en el mundo del trabajo formal". Revista Venezolana de Gerencia, Año 7, № 20, octubre-diciembre, LUZ, Maracaibo.

Iranzo, Consuelo y Richter, Jacqueline (2002b), "Negociación colectiva y género. Estudio del caso venezolano". Informe final de investigación. OIT,Caracas, mimeo.

Iranzo, Consuelo y Patruyo, Thanali (2001), "Consecuencias de la reestructuración económica y política en el sindicalismo venezolano" en el Dossier: El sindicalismo latinoamericano en el marco de la globalización: crisis y retos a comienzos de siglo. Revista Cuadernos del CENDES, Año 18, segunda época, mayo-agosto, Caracas.
Ley Orgánica del Trabajo. G. Ext. 5.152 de fecha 19/06/1997.

Ley Orgánica de Prevención, Condiciones y Medio Ambiente de Trabajo: G.O. N ${ }^{\circ}$ 3.850 de fecha 18 de julio de 1986 .

Ley Orgánica de Protección del Niño y del Adolescente: G.O Ext. 5.266 de fecha 02/10/1998.

Ley de Igualdad de Oportunidad para la Mujer: G.O Ext. 5.398 de fecha 26 de octubre de 1999.

Ley del Seguro Social: G.O. Ext. 4.322 de fecha 03 de octubre de 1991.

Ley del Instituto Nacional de Cooperación Educativa: Ref. Parc. G.O 34.563 de fecha 28 de septiembre de 1990.

Ministerio del trabajo (2001), Memoria.

Reglamento de la Ley Orgánica del Trabajo: G. Ext. 5.292 de fecha 25/01/1999.

Reglamento de la Ley del Instituto Nacional de Cooperación Educativa. G.O 34.563 de fecha 28/09/90.

Reglamento General de la Ley del Seguro Social Obligatorio: G.O Ext.5.398 de fecha 26/10/1999.

Soares, Vera (1998), "Acordos coletivos e as trabalhadoras" en Lais Abramo y Alicia Rangel: Genero e trabalho na sociología latino-americana. Ed. ALAST/ SERT, Sao Paulo. 